\title{
A Retrospective Study of the Clinical Burden of Hospitalized All-Cause and Pneumococcal Pneumonia in Canada
}

\author{
Shelly A. McNeil, ${ }^{1}$ Nawab Qizilbash, ${ }^{2,3}$ Jian Ye, ${ }^{4}$ Sharon Gray, ${ }^{4}$ Giovanni Zanotti, ${ }^{5}$ \\ Samantha Munson, ${ }^{4}$ Nathalie Dartois, ${ }^{6}$ and Craig Laferriere ${ }^{5}$ \\ ${ }^{1}$ Canadian Center for Vaccinology, IWK Health Centre and Nova Scotia Health Authority, Dalhousie University, Halifax, \\ NS, Canada B3K 6 R8 \\ ${ }^{2}$ OXON Epidemiology Ltd., London NW1 2FD, UK \\ ${ }^{3}$ London School of Hygiene \& Tropical Medicine, London WC1E 7HT, UK \\ ${ }^{4}$ Pfizer Inc., Collegeville, PA 19426, USA \\ ${ }^{5}$ Pfizer Canada, Kirkland, QC, Canada H9J 2M5 \\ ${ }^{6}$ Pfizer, 75668 Paris Cedex 14, France
}

Correspondence should be addressed to Shelly A. McNeil; shelly.mcneil@nshealth.ca

Received 28 May 2015; Accepted 6 September 2015

Copyright ( 2016 Shelly A. McNeil et al. This is an open access article distributed under the Creative Commons Attribution License, which permits unrestricted use, distribution, and reproduction in any medium, provided the original work is properly cited.

\begin{abstract}
Background. Routine vaccination against Streptococcus pneumoniae is recommended in Canada for infants, the elderly, and individuals with chronic comorbidity. National incidence and burden of all-cause and pneumococcal pneumonia in Canada (excluding Quebec) were assessed. Methods. Incidence, length of stay, and case-fatality rates of hospitalized all-cause and pneumococcal pneumonia were determined for 2004-2010 using ICD-10 discharge data from the Canadian Institutes for Health Information Discharge Abstract Database. Population-at-risk data were obtained from the Statistics Canada census. Temporal changes in pneumococcal and all-cause pneumonia rates in adults $\geq 65$ years were analyzed by logistic regression. Results. Hospitalization for all-cause pneumonia was highest in children $<5$ years and in adults $>70$ years and declined significantly from $1766 / 100,000$ to $1537 / 100,000$ per year in individuals aged $\geq 65$ years $(P<0.001)$. Overall hospitalization for pneumococcal pneumonia also declined from $6.40 / 100,000$ to $5.08 / 100,000$ per year. Case-fatality rates were stable (11.6\% to $12.3 \%$ ). Elderly individuals had longer length of stay and higher case-fatality rates than younger groups. Conclusions. All-cause and pneumococcal pneumonia hospitalization rates declined between 2004 and 2010 in Canada (excluding Quebec). Direct and indirect effects from pediatric pneumococcal immunization may partly explain some of this decline. Nevertheless, the burden of disease from pneumonia remains high.
\end{abstract}

\section{Introduction}

Streptococcus pneumoniae is an important cause of pneumonia and invasive pneumococcal diseases (IPDs) which are leading causes of morbidity and mortality, particularly in infants and older adults $[1,2]$. Before routine pneumococcal vaccination in Canada, the burden of pneumococcal disease was substantial among all age groups. In 2001, an estimated 565,077 cases of pneumococcal disease in Canada resulted in 3002 deaths, mainly due to pneumonia in the elderly [3]. This clinical burden was associated with the loss of 54,330 lifeyears, and pneumococcal disease incurred an estimated cost to society of $\$ 193$ million (Canadian dollars); IPD represented $17 \%$ of these overall costs [3].

In 2002, the Canadian National Advisory Committee on Immunization (NACI) first recommended 4 doses of 7valent pneumococcal conjugate vaccine $(\mathrm{PCV} 7)$ in routine infant immunization schedules for all children aged $<2$ years and children aged 2-5 years at high risk for pneumococcal infection [4]. Vaccination with PCV7 was implemented in all provinces and territories by 2006 [5]. The programs resulted in dramatic decreases in IPD and isolation of antibioticresistant PCV serotypes, more than halving the rates of IPD in children $[3,6,7]$. 
Although a herd effect has been observed for IPD in Canadian adults [8-10], no such effect has been reported for pneumonia. This is in contrast with the United States, where a herd effect has been demonstrated for the two conditions [11-13].

Healthcare policy makers rely on availability of accurate data on the burden of illness within their region. This paper reports the incidence and case-fatality rates of hospitalized all-cause and pneumococcal pneumonia, and mean length of stay (LOS) of hospitalization for all ages across Canada (excluding Quebec) between 2004 and 2010.

\section{Methods}

2.1. Study Objectives. The primary objective of this study was to quantify the incidence rate of all-cause infectious pneumonia using retrospective data for patients admitted to all hospitals across all provinces and territories in Canada during the study period from 2004 to 2010. Secondary objectives included quantifying the length of hospital stay and the mortality rate associated with all-cause pneumonia and the incidence rate of pneumococcal pneumonia.

2.2. Data Collection. Data were obtained from the Canadian Institute for Health Information (CIHI) Discharge Abstract Database (DAD) [14], which contains demographic, administrative, and clinical data for patients admitted to all hospitals in Canada, except Quebec. Since 2004-2005, all DAD records have been reported using the International Classification of Diseases, Tenth Revision, Canadian Enhancement (ICD-10CA) codes [15]. Data were collected at each hospital from patient administrative and clinical record systems and were compiled each financial year ending 31 March. Hospitalization in Quebec was not included in the analysis because ICD9 diagnosis codes were used in this province during part of the study period.

Data collected included patient demographics, hospitalization information (including the ICD-10-CA codes for the most responsible diagnosis and month and year of hospitalization), in-hospital case-fatality, hospital length of stay (LOS), and province/territory. Cases of hospitalization due to all-cause pneumonia and pneumococcal pneumonia were identified using the corresponding ICD-10-CA codes (Supplemental Table 1 in Supplementary Material available online at http://dx.doi.org/10.1155/2016/3605834). Population-at-risk data were obtained from Statistics Canada census information [16]. Data were provided in an anonymous and aggregate fashion, and ethics approval was not required.

2.3. Data Analyses. Hospitalization data for patients admitted to all hospitals across all provinces and territories in Canada except Quebec (2004-2010) and population at-risk data obtained from Statistics Canada census were used to calculate incidence rate. The incidence per 100,000 persons per year and $95 \%$ confidence intervals (CIs) of hospitalization for each condition were calculated based on Poisson distribution. Case-fatality rates (95\% CIs) were calculated as the number of deaths divided by the corresponding number of hospitalized cases multiplied by 100 . LOS was calculated as the number of days in the hospital and reported as mean with standard deviations (SD). Patient subgroups were defined by age, gender, and province/territory. Cases without sex or age information were excluded. The incidence rates of pneumococcal and all-cause pneumonia in adults aged $\geq 65$ years were investigated by logistic regression analyses using year as the independent variable. All analyses were performed using SAS software (SAS Institute, Cary, NC; version 9.1.3 and version 9.2).

\section{Results}

Between 2004 and 2010, hospitalized cases meeting study criteria ranged from 88,151 (2004-2005) to 89,785 (2009-2010) for all-cause pneumonia and 1563 (2004-2005) to 1315 (20092010) for pneumococcal pneumonia.

3.1. All-Cause Pneumonia. Children aged $<5$ years and adults aged $>70$ years had the highest incidence of hospitalized all-cause pneumonia (Figure 1(a) and Supplemental Table 2). In adults, incidence increased sharply after the age of 60 years, with markedly higher incidences of pneumonia-related hospitalization versus all younger age groups in all years (Figure 1(a) and Table 1). An overall decline in the incidence of hospitalization due to all-cause pneumonia was observed over the study period owing primarily to decreases in the incidence among the youngest children and adults aged $\geq 65$ years. In the <4-year-olds group, incidence fell from 694 (95\% CI: 680-708) in 2004-2005 to 611 (95\% CI: 598-624) in 2009-2010, and in the $\geq 65$-year-olds group incidence fell from 1766 (95\% CI: 1751-1780) to 1537 (95\% CI: 1524-1550) during the same period. In other age groups, the rates of all-cause pneumonia were lower but did not decline over the study period (Figure 1(a)). Logistic regression was used to demonstrate that the decline observed in adults aged $\geq 65$ years (13\%) was statistically significant $(P<0.001$, Figure $2(a))$. In all study years, the incidence of all-cause pneumonia was higher in males than females (Table 1). The frequencies for hospital admissions due to all-cause pneumonia for each province or territory are presented in Figure 1(b). The mean LOS for hospitalization for all-cause pneumonia remained stable over time in the overall population (9.99 days in 20042005 and 10.54 days in 2009-2010) (Table 1) and increased with increasing age.

Overall case-fatality rates associated with all-cause pneumonia were relatively stable over the study period, ranging from $11.6 \%$ in $2009-2010$ to $12.3 \%$ in $2004-2005$ (Table 1 ). Mortality increased with increasing age (Figure 1(c) and Supplemental Table 2) and was the highest in those aged $\geq 80$ years $(19.7 \%-20.9 \%)$. In patients aged $\geq 65$ years, the 2009 2010 case-fatality rate for hospitalized all-cause pneumonia was $16.7 \%$, whereas it was $\leq 1 \%$ in children aged $<10$ years (Table 1). Case-fatality rates varied by province but were relatively stable within each province (Figure $1(\mathrm{~d})$ ). In most study years, case-fatality rates were higher in males than females (Table 1). 


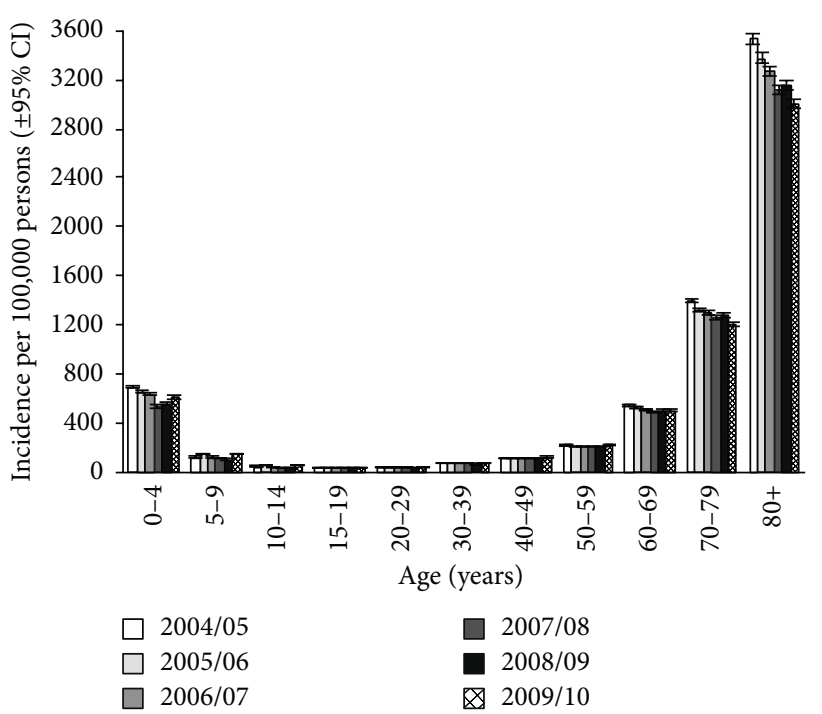

(a)

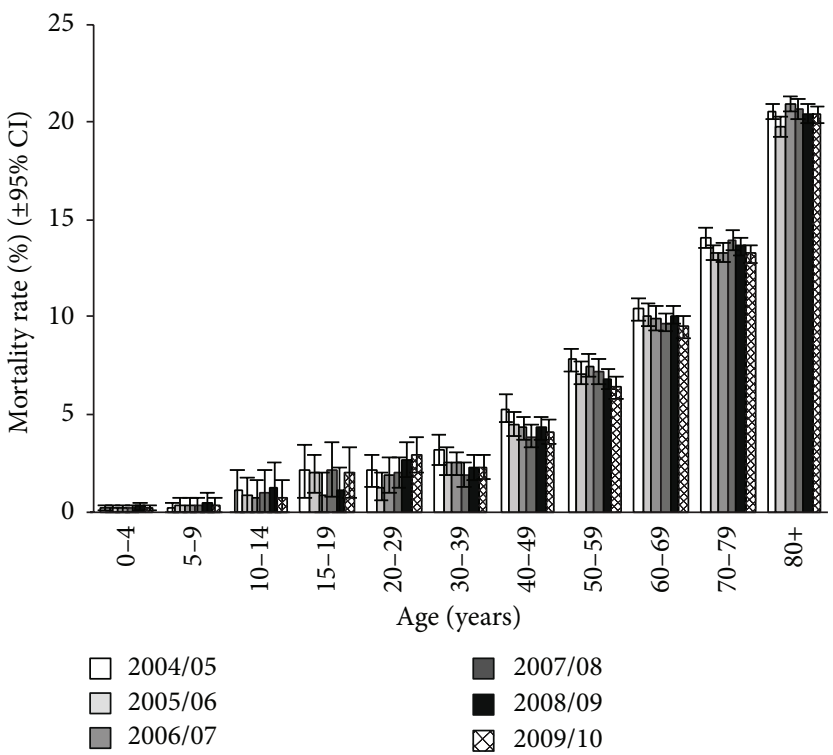

(c)

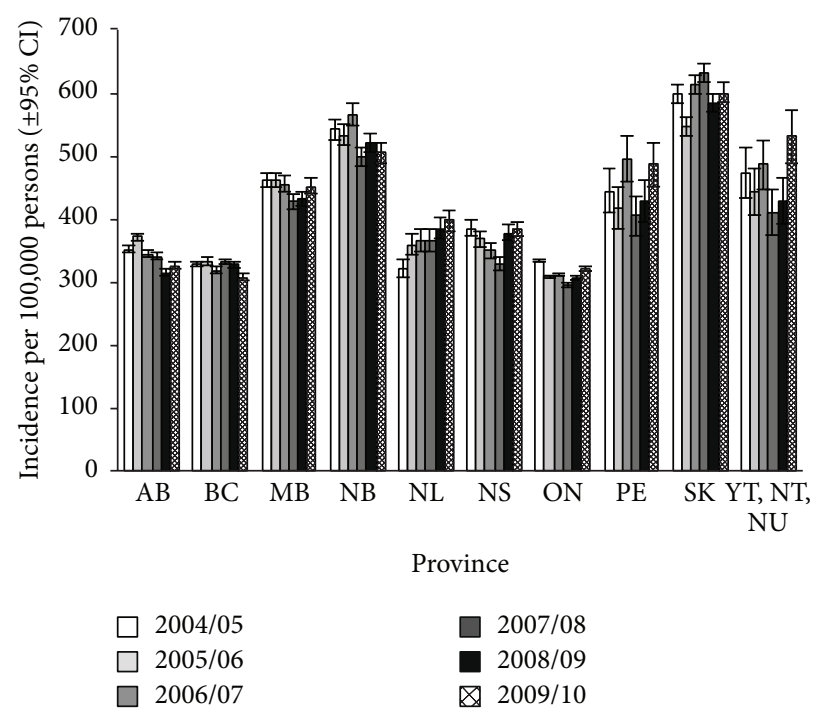

(b)

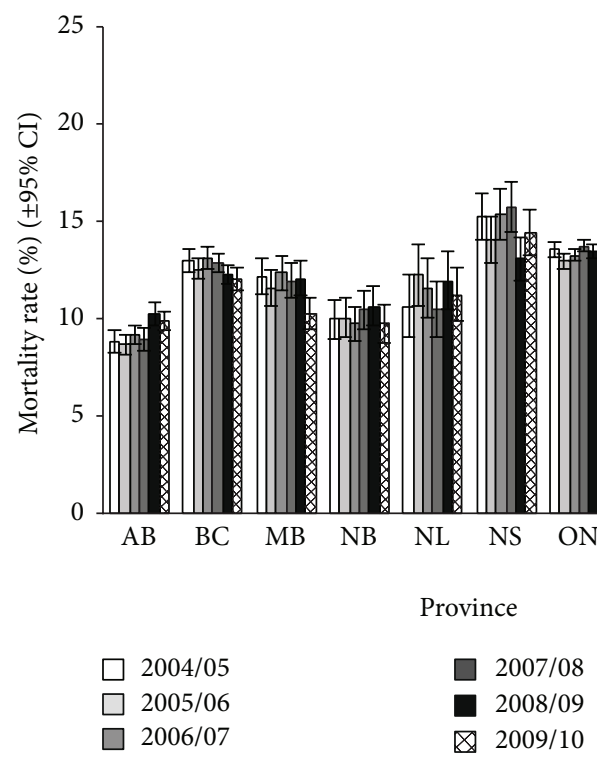

(d)

Figure 1: Annual incidence of hospitalization in Canada from 2004-2005 to 2009-2010 due to all-cause pneumonia by age (a) and province (b); and annual case-fatality rate due to all-cause pneumonia by age (c) and province (d). Error bars indicate $95 \%$ confidence intervals. AB, Alberta; BC, British Columbia; MB, Manitoba; NB, New Brunswick; NL, Newfoundland and Labrador; NS, Nova Scotia; NT, Northwest Territories; NU, Nunavut; PE, Prince Edward Island; SK, Saskatchewan; YT, Yukon.

3.2. Pneumococcal Pneumonia. The highest incidence of hospitalization due to pneumococcal pneumonia occurred in children aged <5 years (10.64/100,000 [95\% CI: 9.02-12.54] in 2004-2005 and 9.14/100,000 [95\% CI: 7.70-10.86] in 2009$2010)$ and in adults aged $\geq 65$ years $(21.27 / 100,000$ [95\% CI: 19.27-22.95] in 2004-2005 and 13.00/100,000 [95\% CI: 11.8614.25] in 2009-2010) (Table 2 and Supplemental Table 3). As with all-cause hospitalized pneumonia, the incidence curve by age was J-shaped, with rates in adults increasing with increasing age (Figure 3(a)).

Across all ages, the annual incidence of hospitalization for pneumococcal pneumonia declined from 6.40/100,000 (95\%
CI: $6.09-6.73$ ) in $2004-2005$ to $5.08 / 100,000$ (95\% CI: $4.81-$ 5.36 ) in 2009-2010 (Table 2). Declines were seen in the 0-4year-olds group from 10.64/100,000 (95\% CI: 9.02-12.54) in 2004-2005 to 7.21/100,000 (95\% CI: 5.93-8.76) in 2008-2009. Declines were also seen in age groups $>50$ years. Of note, the $39 \%$ decline seen in adults aged $\geq 65$ years $(21.27 / 100,000$ [95\% CI: 19.72-22.95] in 2004-2005 to 13.00/100,000 [95\% CI: 11.86-14.25] in 2009-2010) was statistically significant $(P<$ 0.001 , Figure 2(b)). The annual incidence of hospitalized pneumococcal disease was the highest in the Canadian North (Northwest Territories, Yukon, and Nunavut), with rates 


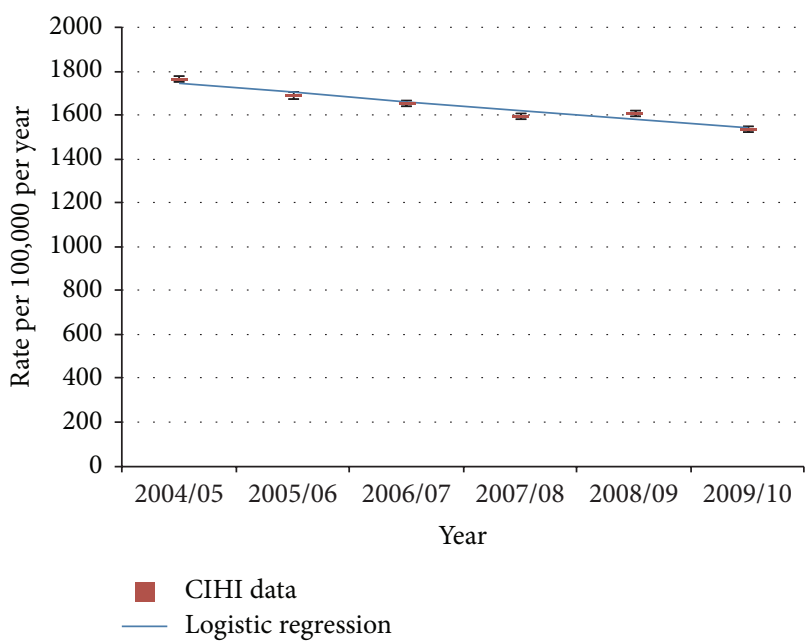

(a)

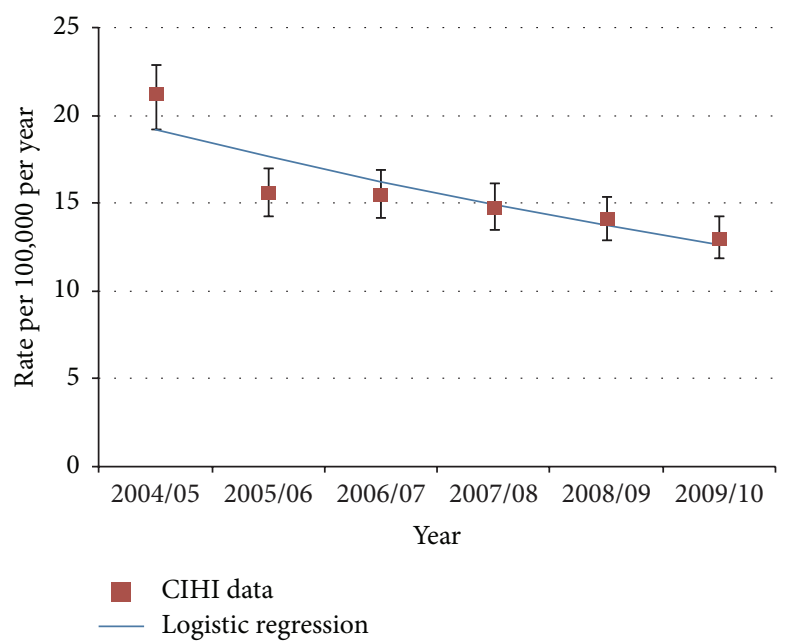

(b)

FIGURE 2: Logistic regression analysis in Canada from 2004-2005 to 2009-2010 in individuals aged $\geq 65$ years for (a) all-cause pneumonia and (b) pneumococcal pneumonia. Error bars indicate 95\% confidence intervals. CIHI, Canadian Institute for Health Information.

TABLE 1: Annual incidence, LOS, and case-fatality rates for hospitalization due to all-cause pneumonia in Canada, from 2004-2005 to 20092010 .

\begin{tabular}{|c|c|c|c|c|c|c|}
\hline & 2004-2005 & $2005-2006$ & $2006-2007$ & $2007-2008$ & 2008-2009 & $2009-2010$ \\
\hline \multicolumn{7}{|l|}{ Annual incidence } \\
\hline $\begin{array}{l}\text { Number of cases/at-risk } \\
\text { population }\end{array}$ & $88151 / 24404747$ & $87050 / 24663298$ & $86679 / 24944522$ & $84909 / 25242310$ & $86839 / 25564644$ & $89785 / 25891827$ \\
\hline \multicolumn{7}{|l|}{$\begin{array}{l}\text { Incidence per } 100,000 \\
\text { persons }(95 \% \mathrm{CI})\end{array}$} \\
\hline Overall & $\begin{array}{c}361 \\
(359,364)\end{array}$ & $\begin{array}{c}353 \\
(351,355)\end{array}$ & $\begin{array}{c}347 \\
(345,350)\end{array}$ & $\begin{array}{c}336 \\
(334,339)\end{array}$ & $\begin{array}{c}340 \\
(337,342)\end{array}$ & $\begin{array}{c}347 \\
(345,349)\end{array}$ \\
\hline$\geq 65$ years of age & $\begin{array}{c}1766 \\
(1751,1780)\end{array}$ & $\begin{array}{c}1692 \\
(1678,1707)\end{array}$ & $\begin{array}{c}1655 \\
(1641,1669)\end{array}$ & $\begin{array}{c}1595 \\
(1582,1609)\end{array}$ & $\begin{array}{c}1611 \\
(1598,1624)\end{array}$ & $\begin{array}{c}1537 \\
(1524,1550)\end{array}$ \\
\hline Males & $\begin{array}{c}382 \\
(379,386)\end{array}$ & $\begin{array}{c}371 \\
(367,374)\end{array}$ & $\begin{array}{c}367 \\
(364,371)\end{array}$ & $\begin{array}{c}356 \\
(353,359)\end{array}$ & $\begin{array}{c}355 \\
(352,358)\end{array}$ & $\begin{array}{c}362 \\
(359,365)\end{array}$ \\
\hline Females & $\begin{array}{c}341 \\
(337,344)\end{array}$ & $\begin{array}{c}336 \\
(332,339)\end{array}$ & $\begin{array}{c}328 \\
(325,331)\end{array}$ & $\begin{array}{c}317 \\
(314,320)\end{array}$ & $\begin{array}{c}324 \\
(321,328)\end{array}$ & $\begin{array}{c}332 \\
(329,335)\end{array}$ \\
\hline \multicolumn{7}{|l|}{ LOS, mean days \pm SD } \\
\hline Overall & $9.99 \pm 16.66$ & $9.92 \pm 15.51$ & $10.30 \pm 17.42$ & $10.67 \pm 18.73$ & $11.03 \pm 18.90$ & $10.54 \pm 20.09$ \\
\hline 0-17 years of age & $3.90 \pm 6.51$ & $3.89 \pm 8.12$ & $3.93 \pm 6.16$ & $3.88 \pm 6.35$ & $3.96 \pm 7.03$ & $3.90 \pm 8.10$ \\
\hline $18-69$ years of age & $9.13 \pm 14.94$ & $8.77 \pm 14.5$ & $9.07 \pm 15.91$ & $9.41 \pm 19.10$ & $9.64 \pm 16.46$ & $9.35 \pm 17.32$ \\
\hline$\geq 70$ years of age & $11.98 \pm 18.77$ & $12.11 \pm 16.95$ & $12.54 \pm 19.50$ & $12.87 \pm 19.84$ & $13.30 \pm 21.31$ & $12.98 \pm 23.18$ \\
\hline \multicolumn{7}{|l|}{ Case-fatality } \\
\hline $\begin{array}{l}\text { Number of deaths/number } \\
\text { of cases }\end{array}$ & $10822 / 88151$ & $10151 / 87050$ & $10539 / 86679$ & $10397 / 84909$ & $10707 / 86839$ & $10419 / 89785$ \\
\hline \multicolumn{7}{|l|}{$\%(95 \% \mathrm{CI})$} \\
\hline Overall & $\begin{array}{c}12.3 \\
(12.1,12.5)\end{array}$ & $\begin{array}{c}11.7 \\
(11.4,11.9)\end{array}$ & $\begin{array}{c}12.2 \\
(11.9,12.4)\end{array}$ & $\begin{array}{c}12.2 \\
(12.0,12.5)\end{array}$ & $\begin{array}{c}12.3 \\
(12.1,12.6)\end{array}$ & $\begin{array}{c}11.6 \\
(11.4,11.8)\end{array}$ \\
\hline$\geq 65$ years of age & $\begin{array}{c}17.1 \\
(16.8,17.4)\end{array}$ & $\begin{array}{c}16.4 \\
(16.1,16.8)\end{array}$ & $\begin{array}{c}17.1 \\
(16.7,17.4)\end{array}$ & $\begin{array}{c}17.1 \\
(16.8,17.5)\end{array}$ & $\begin{array}{c}17.0 \\
(16.7,17.3)\end{array}$ & $\begin{array}{c}16.7 \\
(16.4,17.0)\end{array}$ \\
\hline Males & $\begin{array}{c}12.8 \\
(12.5,13.1)\end{array}$ & $\begin{array}{c}11.9 \\
(11.6,12.2)\end{array}$ & $\begin{array}{c}12.5 \\
(12.2,12.8)\end{array}$ & $\begin{array}{c}12.6 \\
(12.3,12.9)\end{array}$ & $\begin{array}{c}12.9 \\
(12.6,13.3)\end{array}$ & $\begin{array}{c}11.9 \\
(11.6,12.1)\end{array}$ \\
\hline Females & $\begin{array}{c}11.7 \\
(11.4,12.0)\end{array}$ & $\begin{array}{c}11.4 \\
(11.1,11.7)\end{array}$ & $\begin{array}{c}11.7 \\
(11.4,12.1)\end{array}$ & $\begin{array}{c}11.8 \\
(11.5,12.2)\end{array}$ & $\begin{array}{c}11.7 \\
(11.4,12.0)\end{array}$ & $\begin{array}{c}11.3 \\
(11.0,11.6)\end{array}$ \\
\hline
\end{tabular}

CI, confidence interval; LOS, length of stay; SD, standard deviation. 
TABLE 2: Annual incidence, LOS, and case-fatality rates for hospitalization due to pneumococcal pneumonia in Canada, from 2004-2005 to 2009-2010.

\begin{tabular}{|c|c|c|c|c|c|c|}
\hline & 2004-2005 & $2005-2006$ & 2006-2007 & $2007-2008$ & 2008-2009 & 2009-2010 \\
\hline \multicolumn{7}{|l|}{ Annual incidence } \\
\hline $\begin{array}{l}\text { Number of cases/at-risk } \\
\text { population }\end{array}$ & $1563 / 24404747$ & $1307 / 24663298$ & $1420 / 24944522$ & $1395 / 25242310$ & $1219 / 25564644$ & $1315 / 25891827$ \\
\hline \multicolumn{7}{|l|}{$\begin{array}{l}\text { Incidence per 100,000 } \\
\text { persons }(95 \% \mathrm{CI})\end{array}$} \\
\hline Overall & $\begin{array}{c}6.40 \\
(6.09,6.73)\end{array}$ & $\begin{array}{c}5.30 \\
(5.02,5.59)\end{array}$ & $\begin{array}{c}5.69 \\
(5.40,6.00)\end{array}$ & $\begin{array}{c}5.53 \\
(5.24,5.82)\end{array}$ & $\begin{array}{c}4.77 \\
(4.51,5.04)\end{array}$ & $\begin{array}{c}5.08 \\
(4.81,5.36)\end{array}$ \\
\hline$\geq 65$ years of age & $\begin{array}{c}21.27 \\
(19.72,22.95)\end{array}$ & $\begin{array}{c}15.61 \\
(14.30,17.04)\end{array}$ & $\begin{array}{c}15.49 \\
(14.20,16.90)\end{array}$ & $\begin{array}{c}14.78 \\
(13.53,16.14)\end{array}$ & $\begin{array}{c}14.11 \\
(12.90,15.42)\end{array}$ & $\begin{array}{c}13.00 \\
(11.86,14.25)\end{array}$ \\
\hline Males & $\begin{array}{c}7.34 \\
(6.87,7.84)\end{array}$ & $\begin{array}{c}6.03 \\
(5.61,6.48)\end{array}$ & $\begin{array}{c}6.73 \\
(6.29,7.21)\end{array}$ & $\begin{array}{c}6.53 \\
(6.09,6.99)\end{array}$ & $\begin{array}{c}5.66 \\
(5.26,6.09)\end{array}$ & $\begin{array}{c}5.70 \\
(5.30,6.13)\end{array}$ \\
\hline Females & $\begin{array}{c}5.49 \\
(5.09,5.92)\end{array}$ & $\begin{array}{c}4.58 \\
(4.22,4.98)\end{array}$ & $\begin{array}{c}4.67 \\
(4.31,5.06)\end{array}$ & $\begin{array}{c}4.54 \\
(4.19,4.93)\end{array}$ & $\begin{array}{c}3.89 \\
(3.56,4.24)\end{array}$ & $\begin{array}{c}4.47 \\
(4.12,4.85)\end{array}$ \\
\hline \multicolumn{7}{|l|}{ LOS, mean days \pm SD } \\
\hline Overall & $11.93 \pm 17.18$ & $11.07 \pm 18.53$ & $11.37 \pm 18.51$ & $11.54 \pm 17.42$ & $12.16 \pm 17.16$ & $11.31 \pm 18.13$ \\
\hline $0-17$ years of age & $5.96 \pm 8.93$ & $6.45 \pm 10.18$ & $6.35 \pm 7.20$ & $5.76 \pm 6.54$ & $10.36 \pm 18.85$ & $10.18 \pm 31.26$ \\
\hline $18-69$ years of age & $12.24 \pm 17.47$ & $10.56 \pm 14.56$ & $11.75 \pm 21.32$ & $11.10 \pm 17.26$ & $11.75 \pm 14.86$ & $10.59 \pm 13.22$ \\
\hline$\geq 70$ years of age & $13.53 \pm 18.46$ & $13.80 \pm 26.01$ & $12.47 \pm 14.05$ & $14.87 \pm 19.92$ & $13.62 \pm 20.49$ & $13.43 \pm 18.00$ \\
\hline \multicolumn{7}{|l|}{ Case-fatality } \\
\hline $\begin{array}{l}\text { Number of deaths/number } \\
\text { of cases }\end{array}$ & $134 / 1563$ & $95 / 1307$ & $87 / 1420$ & $86 / 1395$ & $83 / 1219$ & $84 / 1315$ \\
\hline \multicolumn{7}{|l|}{$\%(95 \% \mathrm{CI})$} \\
\hline Overall & $\begin{array}{c}8.6 \\
(7.3,10.1)\end{array}$ & $\begin{array}{c}7.3 \\
(6.0,8.8)\end{array}$ & $\begin{array}{c}6.1 \\
(5.0,7.5)\end{array}$ & $\begin{array}{c}6.2 \\
(5.0,7.6)\end{array}$ & $\begin{array}{c}6.8 \\
(5.5,8.4)\end{array}$ & $\begin{array}{c}6.4 \\
(5.2,7.8)\end{array}$ \\
\hline$\geq 65$ years of age & $\begin{array}{c}13.7 \\
(11.3,16.5)\end{array}$ & $\begin{array}{c}12.7 \\
(10.0,15.9)\end{array}$ & $\begin{array}{c}12.7 \\
(10.0,15.9)\end{array}$ & $\begin{array}{c}12.2 \\
(9.6,15.4)\end{array}$ & $\begin{array}{c}11.8 \\
(9.2,15.0)\end{array}$ & $\begin{array}{c}12.0 \\
(9.4,15.4)\end{array}$ \\
\hline Males & $\begin{array}{c}8.9 \\
(7.2,11.0)\end{array}$ & $\begin{array}{c}7.6 \\
(5.9,9.7)\end{array}$ & $\begin{array}{c}6.1 \\
(4.7,8.0)\end{array}$ & $\begin{array}{c}6.5 \\
(5.0,8.4)\end{array}$ & $\begin{array}{c}6.4 \\
(4.8,8.4)\end{array}$ & $\begin{array}{c}5.6 \\
(4.2,7.5)\end{array}$ \\
\hline Females & $\begin{array}{c}8.1 \\
(6.3,10.5) \\
\end{array}$ & $\begin{array}{c}6.8 \\
(5.0,9.2) \\
\end{array}$ & $\begin{array}{c}6.1 \\
(4.5,8.4) \\
\end{array}$ & $\begin{array}{c}5.7 \\
(4.1,7.9) \\
\end{array}$ & $\begin{array}{c}7.4 \\
(5.4,10.0) \\
\end{array}$ & $\begin{array}{c}7.4 \\
(5.5,9.8) \\
\end{array}$ \\
\hline
\end{tabular}

$\mathrm{CI}$, confidence interval; LOS, length of stay; SD, standard deviation.

2-4-fold higher than those in Ontario and Nova Scotia (Figure 3(b)).

The mean LOS for hospitalization due to pneumococcal pneumonia remained stable in the total population over time (11.93 days in 2004-2005 and 11.31 days in 2009-2010; Table 2). Older patients tended to have longer LOS than younger patients. In the overall study population, case-fatality rates for pneumococcal pneumonia remained relatively stable over the study period from $8.6 \%$ (95\% CI: $7.3 \%-10.1 \%$ ) in $2004-2005$ to $6.4 \%$ (95\% CI: $5.2 \%-7.8 \%$ ) in $2009-2010$ (Table 2). A high case-fatality rate was observed among children aged 10-14 years in 2008-2009 (Figure 3(c) and Supplemental Table 3); however, this reflected a single death among only 4 cases. Generally, an increase in case-fatality with increasing age was observed, rising sharply in those aged $\geq 60$ years (Table 2 ). Case-fatality rates varied greatly by province and were highly variable by year within a province (Figure $3(\mathrm{~d})$ ).

\section{Discussion}

From 2004 to 2010, an overall decrease in the incidence of hospitalization for all-cause and pneumococcal pneumonia was observed in Canada in this study. The highest burden of pneumonia leading to hospitalization-all-cause and pneumococcal-was seen in the very young (children aged $<5$ years) and in older adults, particularly those aged $\geq 65$ years. The risk of mortality associated with pneumonia increased with age in older adults. Concomitant with these age-related trends, the mean LOS for all-cause and pneumococcal pneumonia hospital admissions notably increased with advancing age.

The temporal trends in pneumococcal pneumonia incidence observed in several provinces (Figure 3(b)) are similar to those previously reported for IPD from provincial surveillance programs. For example, overall IPD declined in British Columbia from 2008 through 2010 [10], whereas a transient increase in IPD was observed in Alberta in 20062007, followed by a steep decline in 2009-2010 [8]. Overall rates of IPD were not reported for Ontario in a recent publication [9] but the decline of IPD in children aged $<5$ years between 2002 and 2006 may be reflected in the decline in pneumococcal pneumonia seen in Figure 3(b) between 2004-2005 and 2005-2006 for this province. 


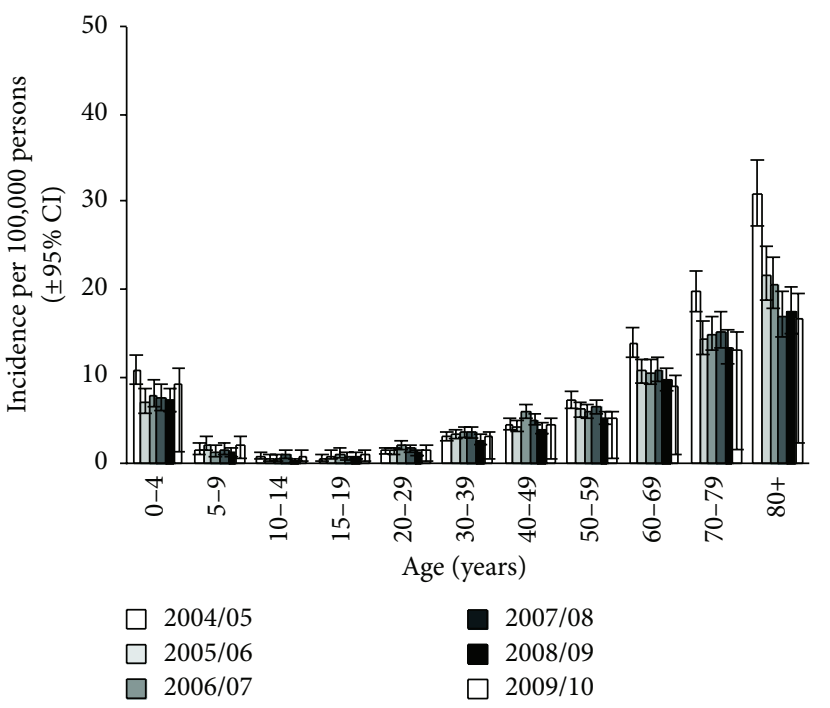

(a)

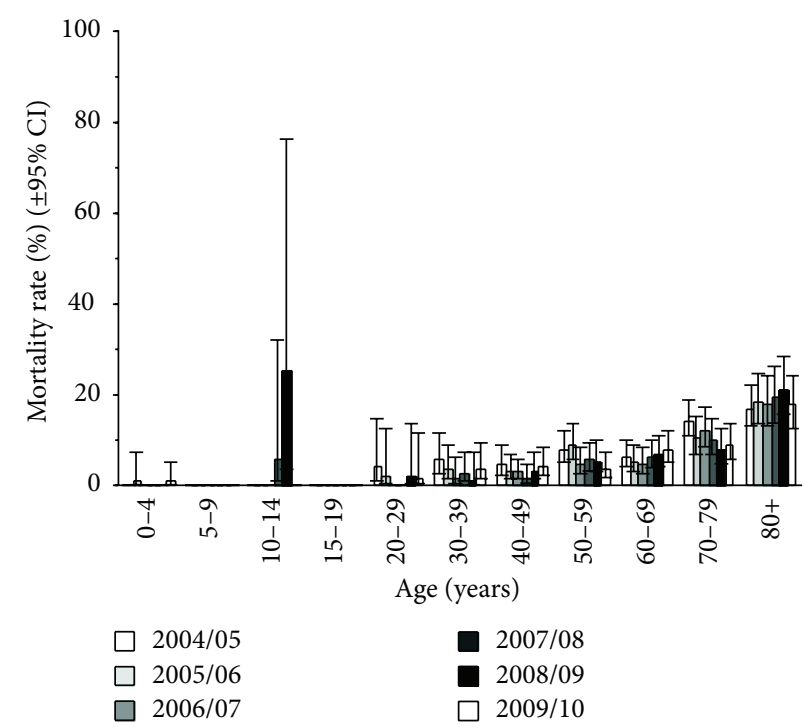

(c)

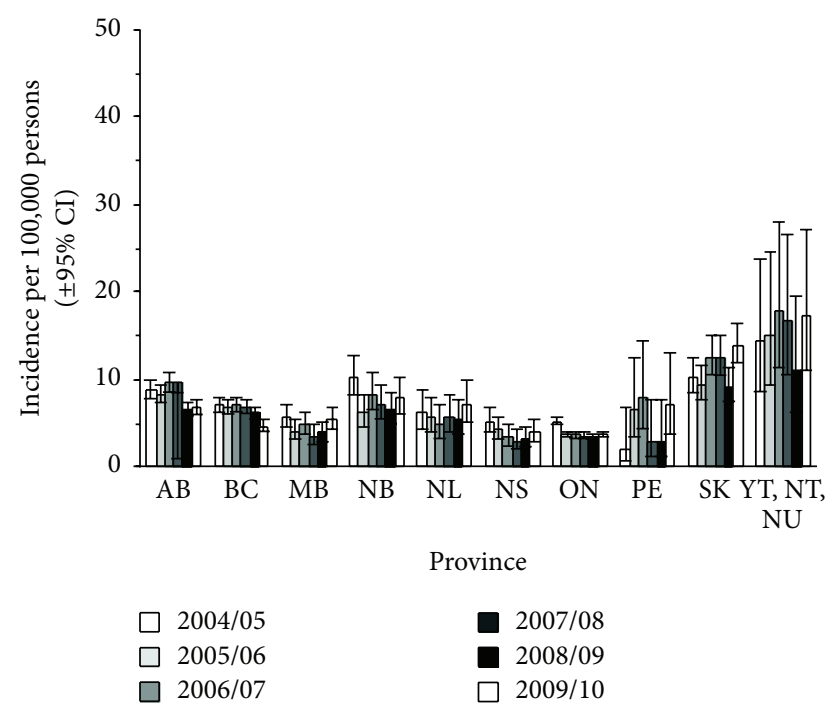

(b)

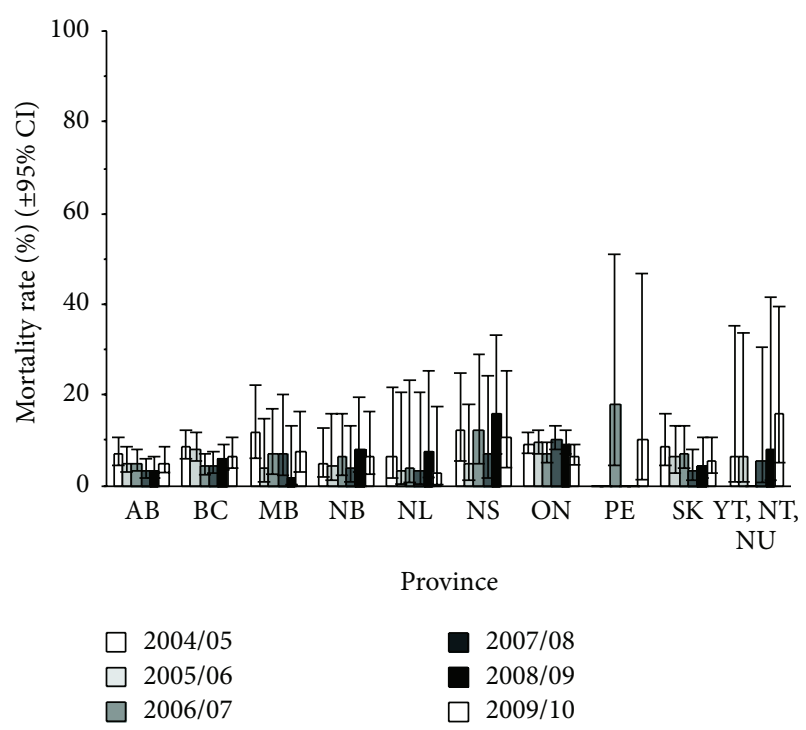

(d)

Figure 3: Annual incidence of hospitalization in Canada from 2004-2005 to 2009-2010 due to pneumococcal pneumonia by age (a) and province (b); and annual case-fatality rate due to pneumococcal pneumonia by age (c) and province (d). Note that case-fatality rates were 0 in PE in 2005-2006, 2007-2008, and 2009-2010 and in YT, NT, and NU in 2006-2007. Error bars indicate 95\% confidence intervals. AB, Alberta; BC, British Columbia; MB, Manitoba; NB, New Brunswick; NL, Newfoundland and Labrador; NS, Nova Scotia; NT, Northwest Territories; NU, Nunavut; PE, Prince Edward Island; SK, Saskatchewan; YT, Yukon.

The case-fatality rate due to IPD in Ontarian adults aged $\geq 65$ years was reported to decline from $29.5 \%$ to $25.7 \%$ between 1995 and $2011(P<0.005)$ [9], but the data shown in Figure 3(d) for mortality from pneumococcal pneumonia in Ontario does not reflect this, possibly because of the shorter time span and variability of the data.

The 39\% decline in pneumococcal pneumonia and 13\% decline in all-cause pneumonia in adults aged $\geq 65$ years between 2004 and 2010 are significant, corresponding to improvements in health measures and warrant attribution. Simonsen and colleagues found a $54 \%$ decline in nonbacteremic pneumococcal pneumonia in US adults aged $\geq 65$ years between baseline 1996-1999 and the 2005-2006 seasons [11]. By using differences in vaccination rates between states, they were able to demonstrate that PCV7 had direct and indirect effects in reducing both IPD and pneumococcal pneumonia in children and adults [11]. Such an approach could not be used in Canada even though publicly funded PCV7 programs were initiated in different provinces at different times between 2002 and 2005 [17]. Active surveillance in Ontario showed that IPD in children $<5$ years old began to decline as early as 2002 , before the publicly funded program began in 2005 [9]. Private sales were estimated at 1 dose per child in the birth cohort during this time [9]. Private sales and 
TABLE 3: Summary of practices and policy changes that could account for declining pneumonia rates in Canadianadults $\geq 65$ years old.

\begin{tabular}{|c|c|c|}
\hline Factor & $\begin{array}{l}\text { Can this explain the decline in all-cause pneumonia } \\
\text { between } 2004 \text { and } 2010 \text { in adults aged } \geq 65 \text { years? }\end{array}$ & Reference \\
\hline Changes in ICD-10 coding practices & No. Would expect changes in all ages groups & NA \\
\hline $\begin{array}{l}\text { Increased use of fluoroquinolones for } \\
\text { lower respiratory tract infection }\end{array}$ & $\begin{array}{l}\text { Maybe. Fluoroquinolone scripts were up in 2004-2005 } \\
\text { but down again in 2008-2009 }\end{array}$ & {$[24,25]$} \\
\hline Smoking amongst adults aged $\geq 65$ years & No. Smoking remained constant at approximately $11 \%$ & Compare [26] with [27] \\
\hline Pneumovax vaccination & $\begin{array}{l}\text { No. PPSV } 23 \text { immunization rates in adults aged } \geq 65 \\
\text { years were stable between } 2006 \text { and } 2010 \text { at } \\
\text { approximately } 38 \%\end{array}$ & {$[28]$} \\
\hline Influenza vaccination & $\begin{array}{l}\text { No. Influenza immunization declined from } 69.9 \% \text { in } \\
2006 \text { to } 52.8 \% \text { in } 2010 \text { in adults aged } \geq 65 \text { years }\end{array}$ & {$[28]$} \\
\hline $\begin{array}{l}\text { New clinical pathway for treatment in } \\
\text { long-term care facilities, rather than in } \\
\text { the hospital }\end{array}$ & No. Decline began before publication of protocol & {$[29]$} \\
\hline $\begin{array}{l}\text { Change in Infectious Disease Society of } \\
\text { America Guidelines for the management } \\
\text { of community-acquired pneumonia }\end{array}$ & No. Decline began before publication of guidelines & {$[30]$} \\
\hline $\begin{array}{l}\text { New guidelines for the treatment of acute } \\
\text { exacerbations of chronic bronchitis }\end{array}$ & $\begin{array}{l}\text { Yes. Focused antibiotic treatment of Groups } 2 \text { and } 3 \\
\text { AECOPD published in } 2003\end{array}$ & {$[22]$} \\
\hline
\end{tabular}

AECOPD: acute exacerbations of chronic obstructive pulmonary disease; ICD: International Classification of Diseases; NA: not applicable; PPSV23: 23-valent pneumococcal polysaccharide vaccine.

lack of information on coverage rates make it difficult to apply the same methodology to demonstrate that the reduction of pneumonia was due to indirect effects in Canada.

Reduction of vaccine serotype IPD in Canadian adults $\geq 65$ years old has been observed from surveillance data in Alberta, British Columbia, Ontario, and Quebec [8-10, 18]; however, serotype replacement occurred in Ontario and Quebec to the extent that there has not been a decline in the overall rate of IPD $[9,18]$. In a Quebec study of hospital admissions for pneumonia, in contrast to reductions seen in the children $<5$ years old after the introduction of a catch-up program with PCV7 in December 2004 [19], there was no reduction in hospitalization for pneumonia in adults aged $\geq 65$ years between 1996 and 2007 [20]. A decline in admissions was noted in younger age groups in 1999, which was attributed to changes in infectious diseases guidelines published in 1998 [20].

The present data, together with previously published reports [5], are consistent with the assertion that vaccination programs in Canada have had an impact on the incidence of pneumococcal disease, particularly among children aged $<4$ years and adults aged $\geq 65$ years. However, disease incidence and associated health-service utilization remain high, with little change in hospital LOS or case-fatality rates over time, suggesting a continuing need to improve the uptake and coverage of available vaccines in older adults and at-risk groups and to continue development programs that offer the prospect of new higher-valent vaccines targeting additional serotypes.

The decline in the rate of all-cause pneumonia we report was 27 times greater than the decline in pneumococcal pneumonia ( -229 compared to -8.27 cases per 100,000 per year). Even though nonbacteremic pneumococcal pneumonia may go undiagnosed, the incidence rate is estimated to be only 3 to 5 times higher than invasive disease [21]. Thus, it is likely that other factors accounted for the decline in all-cause pneumonia in adults aged $\geq 65$ years. Other factors hypothetically contributing to the decline of all-cause pneumonia are tabulated in Table 3. Only the last item in the list, the Canadian Thoracic Society guidelines published in 2003 for the treatment of acute exacerbation of chronic bronchitis [22], appears timed to explain the decrease in allcause pneumonia. Canada was the first country to adopt these guidelines targeting patients with greatest risk for a poor outcome and who were likely to benefit most from early antibiotic treatment [23].

The importance of chronic pulmonary disease in pneumococcal pneumonia was demonstrated in a recent efficacy study of a 13-valent pneumococcal conjugate vaccine against pneumococcal community-acquired pneumonia (CAP) in adults aged $\geq 65$ years [31]. While $10.2 \%$ of the 84,496 subjects recruited into this study self-reported with chronic pulmonary disease [31], 59\% of the 139 subjects diagnosed with vaccine-type pneumococcal pneumonia had physiciandiagnosed chronic pulmonary disease (Pfizer Inc.; data on file). Likewise, other high risk groups such as diabetics, persons with heart disease, and persons with multiple comorbidities made up the majority of subjects suffering from pneumococcal vaccine-type CAP.

It is likely that both the indirect effects from the pediatric PCV7 program and the early treatment of patients with acute exacerbation of chronic obstructive pulmonary disease helped to reduce the rate of all-cause pneumonia in Canada during the time period in this study, but there is insufficient information to be able to quantify each contribution.

This study has several limitations. Sample sizes were small in some provinces/territories because of small populations. Variations in incidence and case-fatality rates by province 
may reflect differences in practices (e.g., only very sick patients may be hospitalized in some provinces). Cases treated as outpatients were not included, leading to probable underreporting of incidence. Although a major strength of the study is that the DAD provides comprehensive data on hospitalization and the census population data provide an appropriate denominator to calculate hospitalized incidence rates, data were derived from ICD-10-CA coding based on physician notes, the quality of which is not readily available at the CIHI. The incidence of hospitalization due to pneumococcal pneumonia was $4.77-6.40 / 100,000$ versus $336-361 / 100,000$ for all-cause pneumonia. Given that approximately $30 \%$ of all-cause pneumonia may be pneumococcal pneumonia [21], it is likely that a specific diagnosis of pneumococcal pneumonia is underreported. This is not surprising given that a specific etiology of hospitalized pneumonia is rarely identified except in cases of IPD. Although the diagnosis of pneumococcal pneumonia by ICD-10-CA coding has relatively low sensitivity, it is likely to be highly specific (i.e., cases assigned this code are very likely to be true cases of pneumonia related to $S$. pneumonia). This method for identifying cases is influenced not only by clinical coding practices, but also by changes in microbiologic testing practices, such as increased use of pneumococcal urinary antigen testing [32]. Microbial etiology was established for $67 \%$ of 184 patients presenting with CAP when a PCR assay was used, versus $60 \%$ with conventional methods [33], and S. pneumoniae was the leading causative agent. Any of these factors could lead to an underestimation of pneumococcal pneumonia cases. However, the incidence of pneumococcal pneumonia for adults aged $\geq 65$ years in 2009-2010 in the current study $(13 / 100,000)$ is similar to that seen for IPD in 2010 in Alberta [8] and British Columbia [10] and slightly lower than that in Ontario [9].

The exclusion of influenza-related codes, such as J11.0 (influenza with pneumonia, virus not identified), means that not all cases of hospitalization linked to pneumonia were included within the all-cause or pneumococcal pneumonia category. Data on comorbidities and concomitant risk factors for pneumonia were not included in this analysis. Respiratory viruses are frequently found in mixed infections with $S$. pneumoniae [33]. Finally, a more complete picture of vaccine impact and potential serotype replacement would emerge if serotype data were available. Although serotype 19A proportionally increased in Canada in the post-PCV7 era, the effect of PCV13 vaccination remains unknown [34]. In areas with $<70 \%$ vaccine coverage, data showing increases in non-PCV serotypes should be interpreted cautiously [35].

\section{Conclusions}

In this retrospective burden of disease study, the incidence of all-cause and pneumococcal pneumonia requiring hospitalization decreased between 2004 and 2010 across Canadian provinces in the total population and in all age groups analyzed. Case-fatality rates associated with hospitalized allcause and pneumococcal pneumonia were age-related, with increasing age associated with greater mortality. Despite the benefits of national vaccination programs, the burden of all-cause and pneumococcal disease in Canada remains high, particularly in younger children and older adults.

\section{Abbreviations \\ CAD: $\quad$ Canadian dollars \\ CAP: Community-acquired pneumonia \\ CI: Confidence interval \\ CIHI: Canadian Institute for Health Information \\ DAD: Discharge Abstract Database \\ ICD-10-CM: International Classification of Diseases, Tenth Revision, Canadian Modification \\ IPD: Invasive pneumococcal disease \\ LOS: $\quad$ Length of stay \\ PCV: $\quad$ Pneumococcal conjugate vaccine \\ PPSV23: 23-valent pneumococcal polysaccharide vaccine.}

\section{Conflict of Interests}

Shelly A. McNeil has received grant funding from Pfizer. Nawab Qizilbash is an employee of OXON Epidemiology Ltd. who performed the research described in this paper, funded by Pfizer. Jian Ye is a former employee of On Assignment Inc. and was contracted to Pfizer Inc., Collegeville, PA, USA. at the time of this study. Sharon Gray and Samantha Munson are employees of Pfizer Inc., Collegeville, PA, USA. Craig Laferriere is an employee of Pfizer, Canada, and Giovanni Zanotti is an employee of Pfizer Inc., New York, New York, USA. Nathalie Dartois is an employee of Pfizer France.

\section{Authors' Contribution}

Shelly A. McNeil contributed to study concept and design, interpretation of the results, drafting and reviewing the paper, and approval of the final paper. Nawab Qizilbash contributed to study concept and design, the statistical analysis plan, interpretation of the results, drafting and reviewing the paper, and approval of the final paper. Jian Ye contributed to study design, interpretation of the results, reviewing the paper, and approval of the final paper. Giovanni Zanotti contributed to study design, interpretation of the results, reviewing the paper, and approval of the final paper. Nathalie Dartois contributed to interpretation of the results, reviewing the paper, and approval of the final paper. Sharon Gray contributed to study concept and design, interpretation of results, drafting and reviewing the paper, and approval of the final paper. Samantha Munson contributed to interpretation of the results, drafting and reviewing the paper, and approval of the final paper. Craig Laferriere contributed to interpretation of the results, drafting and reviewing the paper, and approval of the final paper.

\section{Acknowledgments}

This study was sponsored by Wyeth which was acquired by Pfizer in October 2009. The authors would like to 
thank the programmers at the Canadian Institute for Health Information (CIHI) for case data extraction from the Discharge Abstract Database (DAD). Parts of this material are based on data and information provided by the CIHI. However, the analyses, conclusions, opinions, and statements expressed herein are those of the authors, and not those of the CIHI. The authors would like to thank Dr. Ron Grossman (Trillium Health Partners, Mississauga, ON) for a critical review of the paper. The authors would also like to acknowledge helpful discussions with the following physicians: Tim Bood (Dartmouth General Hospital, Dartmouth, NS), Nicole LeSaux (CHEO Research Institute, Ottowa, ON), Mark Loeb (McMaster University, Hamilton, ON), Tom Marrie (Dalhousie University, Halifax, NS), Allison McGeer (Mount Sinai Hospital, Toronto, ON), Brian Ward (McGill University Health Centre, Pierrefonds, QC), and Karl Weiss (Hôpital Maisonneuve-Rosemont, Université de Montréal, QC). Medical writing support was provided by Nancy Price, Ph.D., at Excerpta Medica, and Daniel E. McCallus, Ph.D., at Complete Healthcare Communications, Inc., both funded by Pfizer Inc.

\section{References}

[1] World Health Organization, The Global Burden of Disease: 2004 Update, World Health Organization, Geneva, Switzerland, 2008.

[2] K. L. O’Brien, L. J. Wolfson, J. P. Watt et al., "Burden of disease caused by Streptococcus pneumoniae in children younger than 5 years: global estimates," The Lancet, vol. 374, no. 9693, pp. 893902, 2009.

[3] A. Morrow, P. De Wals, G. Petit, M. Guay, and L. J. Erickson, "The burden of pneumococcal disease in the Canadian population before routine use of the seven-valent pneumococcal conjugate vaccine," Canadian Journal of Infectious Diseases and Medical Microbiology, vol. 18, no. 2, pp. 121-127, 2007.

[4] National Advisory Committee on Immunizations (NACI), "Statement on recommended use of pneumococcal conjugate vaccine," August, 2014, http://www.collectionscanada.gc.ca/webarchives/20071125012007/http://www.phac-aspc.gc.ca/publicat/ccdr-rmtc/02pdf/acs28-2.pdf.

[5] J. Kellner, "Update on the success of the pneumococcal conjugate vaccine," Paediatrics and Child Health, vol. 16, pp. 233-240, 2011.

[6] J. A. Bettinger, D. W. Scheifele, J. D. Kellner et al., "The effect of routine vaccination on invasive pneumococcal infections in Canadian children, Immunization Monitoring Program, Active 2000-2007," Vaccine, vol. 28, no. 9, pp. 2130-2136, 2010.

[7] J. D. Kellner, O. G. Vanderkooi, J. MacDonald, D. L. Church, G. J. Tyrrell, and D. W. Scheifele, "Changing epidemiology of invasive pneumococcal disease in Canada, 1998-2007: update from the calgary-area Streptococcus pneumoniae research (CASPER) study," Clinical Infectious Diseases, vol. 49, no. 2, pp. 205-212, 2009.

[8] J. Leal, O. G. Vanderkooi, D. L. Church, J. MacDonald, G. J. Tyrrell, and J. D. Kellner, "Eradication of invasive pneumococcal disease due to the seven-valent pneumococcal conjugate vaccine serotypes in Calgary, Alberta," Pediatric Infectious Disease Journal, vol. 31, no. 9, pp. e169-e175, 2012.

[9] W. Rudnick, Z. Liu, A. Shigayeva et al., "Pneumococcal vaccination programs and the burden of invasive pneumococcal disease in Ontario, Canada, 1995-2011," Vaccine, vol. 31, no. 49, pp. 5863-5871, 2013.

[10] V. Sahni, M. Naus, L. Hoang, G. J. Tyrrell, I. Martin, and D. M. Patrick, "The epidemiology of invasive pneumococcal disease in British Columbia following implementation of an infant immunization program: increases in herd immunity and replacement disease," Canadian Journal of Public Health, vol. 103, no. 1, pp. 29-33, 2012.

[11] L. Simonsen, R. J. Taylor, Y. Young-Xu, M. Haber, L. May, and K. P. Klugman, "Impact of pneumococcal conjugate vaccination of infants on pneumonia and influenza hospitalization and mortality in all age groups in the United States," mBio, vol. 2, no. 1, pp. e00309-e003010, 2011.

[12] T. Pilishvili, C. Lexau, M. M. Farley et al., "Sustained reductions in invasive pneumococcal disease in the era of conjugate vaccine," Journal of Infectious Diseases, vol. 201, no. 1, pp. 32-41, 2010.

[13] C. G. Whitney, M. M. Farley, J. Hadler et al., "Decline in invasive pneumococcal disease after the introduction of proteinpolysaccharide conjugate vaccine," The New England Journal of Medicine, vol. 348, no. 18, pp. 1737-1746, 2003.

[14] Canadian Institute for Health Information DAD, August 2014, http://www.cihi.ca/CIHI-ext-portal/internet/en/document/ types+of+care/hospital+care/acute+care/dad_metadata.

[15] International Statistical Classification of Diseases and Related Health Problems 10th Revision-Canadian Enhancement, August, 2014, http://www.cihi.ca/cihi-ext-portal/internet/en/ document/standards+and+data+submission/standards/classification+and+coding/codingclass_icd10.

[16] Statistics Canada, August 2014, http://www.statcan.gc.ca/startdebut-eng.html.

[17] National Advisory Committee on Immunizations (NACI), “Update on pediatric invasive pneumococcal disease and recommended use of conjugate pneumococcal vaccines," August, 2014, http://www.phac-aspc.gc.ca/publicat/ccdr-rmtc/10pdf/36acs-3.pdf.

[18] Laboratoire de Santé Publique du Québec, Programme de Surveillance du Pneumocoque, Rapport, 2013, https://www .inspq.qc.ca/pdf/publications/1946_Programme_Surveillance Pneumocoque.pdf.

[19] P. De Wals, E. Robin, E. Fortin, R. Thibeault, M. Ouakki, and M. Douville-Fradet, "Pneumonia after implementation of the pneumococcal conjugate vaccine program in the province of Quebec, Canada," Pediatric Infectious Disease Journal, vol. 27, no. 11, pp. 963-968, 2008.

[20] P. De Wals, M. Carbon, E. Fortin, J. Pepin, and M. DouvilleFradet, "Vaccination of children with pneumococcal conjugate vaccine had no impact on hospital admissions in adults in Quebec," in Proceedings of the 51st Interscience Conference on Antimicrobial Agents and Chemotherapy, Boston, Mass, USA, September 2010.

[21] M. A. Said, H. L. Johnson, B. A. S. Nonyane, M. Deloria-Knoll, and K. L. OBrien, "Estimating the burden of pneumococcal pneumonia among adults: a systematic review and metaanalysis of diagnostic techniques," PLoS ONE, vol. 8, no. 4, Article ID e60273, 2013.

[22] M. S. Balter, J. La Forge, D. E. Low et al., "Canadian guidelines for the management of acute exacerbations of chronic bronchitis: executive summary," Canadian Respiratory Journal, vol. 10, no. 5, pp. 248-258, 2003. 
[23] M. Miravitlles and A. Anzueto, "Antibiotics for acute and chronic respiratory infection in patients with chronic obstructive pulmonary disease," American Journal of Respiratory and Critical Care Medicine, vol. 188, no. 9, pp. 1052-1057, 2013.

[24] J. M. Conly, "Antimicrobial resistance programs in Canada 1995-2010: a critical evaluation," Antimicrobial Resistance and Infection Control, vol. 1, article 10, 2012.

[25] S. N. Patel, A. McGeer, R. Melano et al., "Susceptibility of Streptococcus pneumoniae to fluoroquinolones in Canada," Antimicrobial Agents and Chemotherapy, vol. 55, no. 8, pp. 37033708, 2011.

[26] Canadian Council on Social Development, Health of Canadians, April 2015, http://www.ccsd.ca/factsheets/health/index .htm.

[27] Government of Canada. Statistics Canada, "Smoking 2010," April 2015, http://www.statcan.gc.ca/pub/82-625-x/2011001/ article/11468-eng.htm.

[28] Public Health Agency Canada, "Vaccine coverage amongst adult Canadians: results from the 2012 adult National Immunization Coverage (aNIC) survey," August 2014, http://www .phac-aspc.gc.ca/im/nics-enva/vcac-cvac-eng.php.

[29] M. Loeb, S. C. Carusone, R. Goeree et al., "Effect of a clinical pathway to reduce hospitalizations in nursing home residents with pneumonia: a randomized controlled trial," The Journal of the American Medical Association, vol. 295, no. 21, pp. 25032510, 2006.

[30] L. A. Mandell, R. G. Wunderink, A. Anzueto et al., "Infectious Diseases Society of America/American Thoracic Society Consensus Guidelines on the management of community-acquired pneumonia in adults," Clinical Infectious Diseases, vol. 44, no. 2, pp. S27-S72, 2007.

[31] M. J. Bonten, S. M. Huijts, M. Bolkenbaas et al., "Polysaccharide conjugate vaccine against pneumococcal pneumonia in adults," The New England Journal of Medicine, vol. 372, no. 12, pp. 1114$1125,2015$.

[32] M. R. Couturier, E. H. Graf, and A. T. Griffin, "Urine antigen tests for the diagnosis of respiratory infections: legionellosis, histoplasmosis, pneumococcal pneumonia," Clinics in Laboratory Medicine, vol. 34, no. 2, pp. 219-236, 2014.

[33] N. Johansson, M. Kalin, T.-L. Annika, C. G. Giske, and J. Hedlund, "Etiology of community-acquired pneumonia: Increased microbiological yield with new diagnostic methods," Clinical Infectious Diseases, vol. 50, no. 2, pp. 202-209, 2010.

[34] X. Deng, D. Church, O. G. Vanderkooi, D. E. Low, and D. R. Pillai, "Streptococcus pneumoniae infection: a Canadian perspective," Expert Review of Anti-Infective Therapy, vol. 11, no. 8, pp. 781-791, 2013.

[35] D. R. Feikin, E. W. Kagucia, J. D. Loo et al., "Serotype-specific changes in invasive pneumococcal disease after pneumococcal conjugate vaccine introduction: a pooled analysis of multiple surveillance sites," PLoS Medicine, vol. 10, no. 9, Article ID e1001517, 2013. 


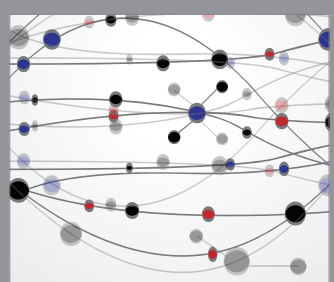

The Scientific World Journal
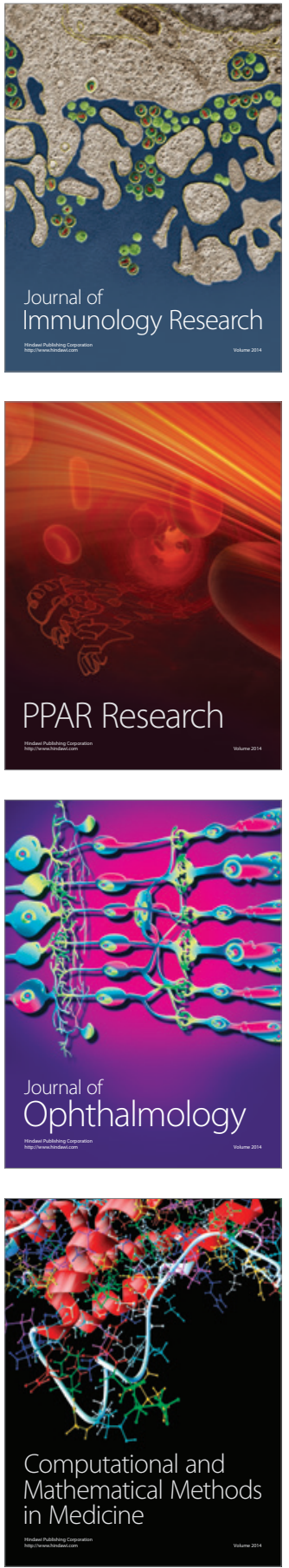

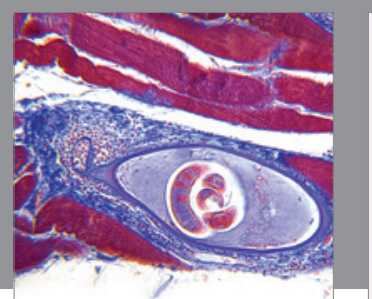

Gastroenterology Research and Practice

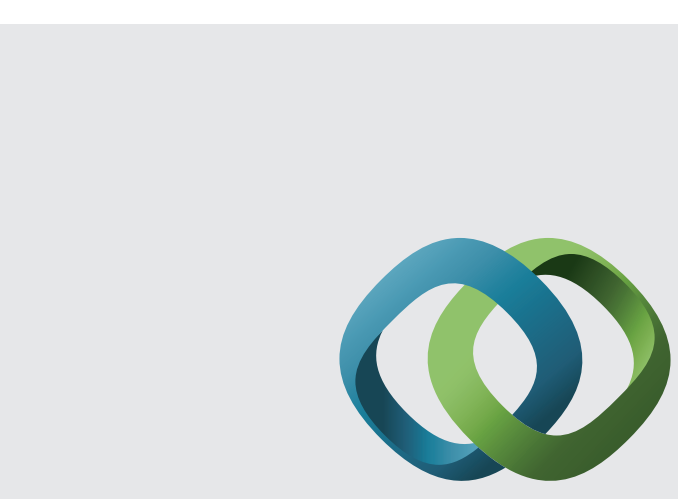

\section{Hindawi}

Submit your manuscripts at

http://www.hindawi.com
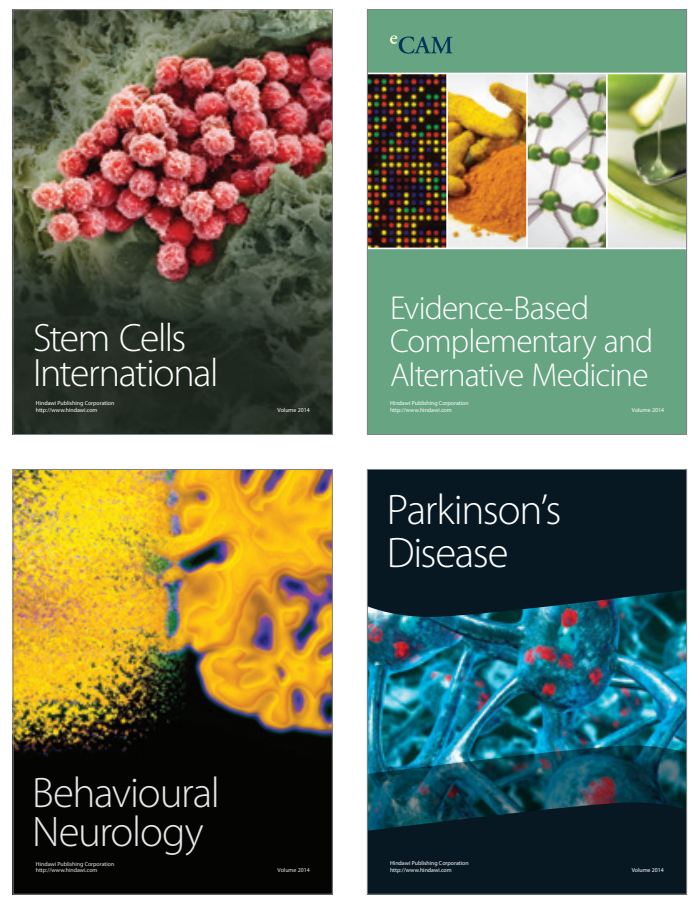
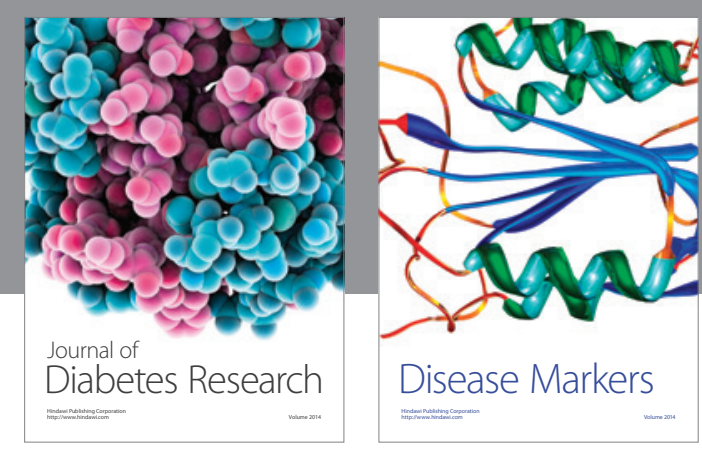

Disease Markers
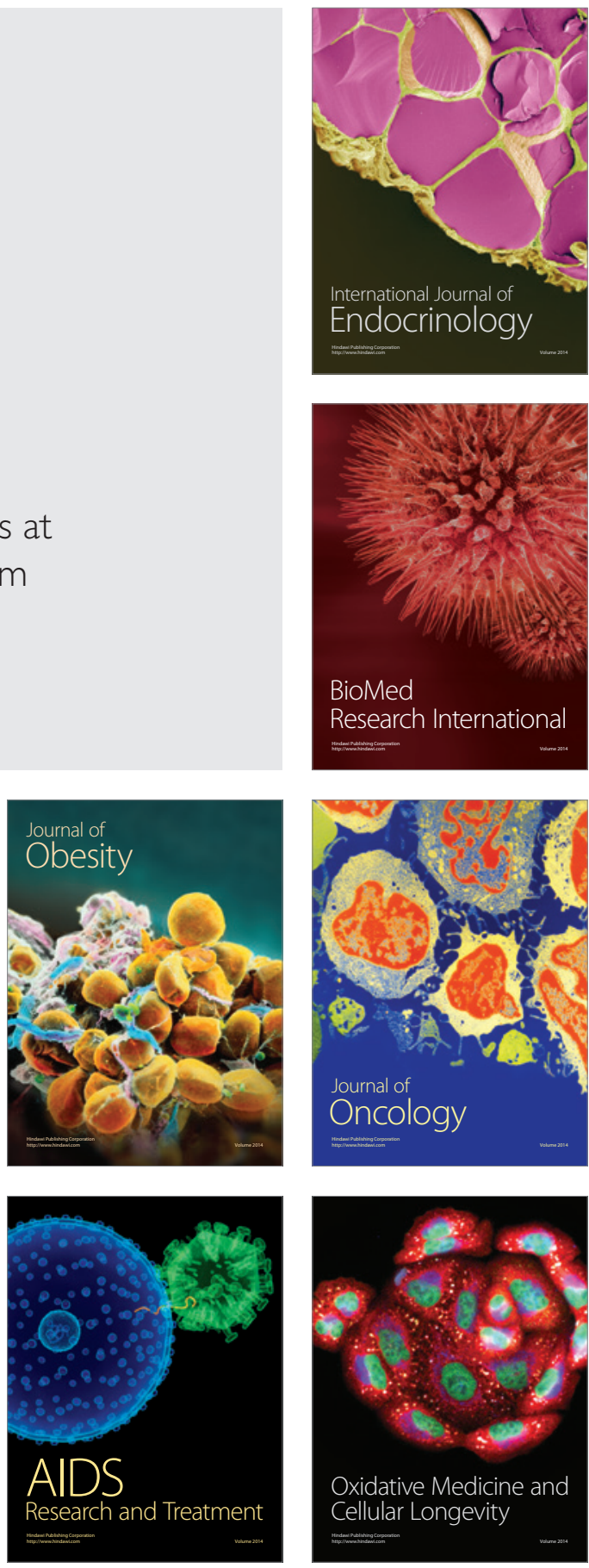